\title{
Discurso constitucional colonial: um olhar para a decolonialidade e para o "novo" Constitucionalismo Latino-Americano
}

\author{
Discourse constitutional colonial: a look for \\ decoloniality and the "new" hispanic constitutionalism
}

\author{
Raquel Fabiana Lopes Sparemberger \\ Eloise da Silveira Petter Damázio*
}

\section{Resumo}

Este artigo trata do conceito de constitucionalismo por meio de uma lógica colonialista, exploradora e genocida, que se justificou e se consolidou a partir de categorias "universais", como Constituição e Estado. Trata-se de ideias localizadas que são impostas como sendo o melhor para todos. $O$ constitucionalismo, nesse contexto, assume historicamente um caráter moderno/colonial que resulta na subalternização de todo e qualquer saber não enquadrado no modelo pretensamente universal de Constituição. Aborda, nesse sentido, uma possível ruptura de tal perspectiva epistêmica moderno/colonial e subalternizadora, a partir do "novo constitucionalismo latino-americano". Visa, sobretudo, questionar os marcos teóricos e epistêmicos do constitucionalismo moderno/colonial e uma ressignificação deste a partir de sujeitos e saberes tradicionalmente subalternizados. Trata-se de um processo descolonial do constitucionalismo que pode representar uma mudança de época com diferentes forças atuantes a partir de diferentes formas de pensamento que não almejam se estabelecer como universais.

Palavras-chave: Constitucionalismo. Colonial. Subalterno. Descolonial.

Pós-doutora em Direito pela Universidade Federal de Santa Catarina - UFSC. Doutora em Direito pela Universidade Federal do Paraná - UFPR. Professora adjunta da Universidade Federal do Rio Grande -FURG, professora do Programa de Mestrado em Direito da Universidade Federal do Rio Grande -FURG. Professora dos cursos de graduação e do Programa de Mestrado em Direito da Faculdade de Direito da Fundação Escola Superior do Ministério Público-FMP Rio Grande RS - Brasil. Email: fabiana7778@hotmail.com

* Doutora em Direito pela Universidade Federal de Santa Catarina (2011). Florianópolis - SCBrasil. Email: eloisepetter@yahoo.com.br 


\section{Abstract}

This work deals with the concept of constitutionalism basedon a colonialist approach, as a exploratory and genocidal practice which was justified and consolidated from "universal" categories such as the Constitution and the State. They are located ideas that are impose das being the best for everyone. The constitucionalism, in this context, historical lyhasassumed a modern/ colonial dimension resulting in a subordinate position of eachand every know ledge that is not included in thesupposedly universal model of Constitution. It also approaches, in theseterms, possible disruption of this modern/colonial epistemic perspective,from " the new Latin American constitucionalism". It aims, specially to question the theoretical and epistemic frameworkof the modern/ colonial constitucionalism and the redefinition of it starting from the traditionally subordinated subjects and knowledge. This is a un colonial process of constitucionalism that could representa massive era change with different acting forces from distinct ways of thinking that are not aspiring to be established as universals.

Keywords: constitutionalism, Colonial, Subordinate, Uncolonial.

\section{Introdução}

A ideia de constitucionalismo como preservação de certas regras jurídicas fundamentais que seriam limitadoras do poder estatal e garantiriam as liberdades individuais aparece no contexto das revoluções liberais burguesas, isto é, na passagem do século XVIII para o século XIX. Surgem nesse cenário as primeiras constituições modernas (Estados Unidos em 1787 e na França em 1791), materializadas em documentos escritos e aprovadas mediante um procedimento formal e solene.

Trata-se de um momento no qual se solidifica um novo modelo de Estado, o Estado-nação, que emerge como contraponto ao Estado absolutista. 
Mesmo sendo um fenômeno histórico, político e localizado geograficamente, o constitucionalismo ocidental se estabeleceu ao longo do tempo sob o manto da universalidade epistêmica.

A universalidade epistêmica diz respeito à pretensão de cientistas e filósofos iluministas - nesse caso específico, os teóricos constitucionalistas - de se situarem como sujeitos detentores de uma racionalidade universal e assim qualificados a dizer verdades sobre todos os povos do planeta. Ou seja, acreditam que estão acima das relações históricas e políticas, desse modo, podem produzir discursos constitucionais verdadeiros que representariam o melhor para toda a humanidade.

A metodologia a ser empreendida é a decolonial, pois busca desconstruir conceitos e premissas construídos de forma apriorística, de modo a, intersubjetivamente, discutir as bases histórico-filosóficas que subjazem ao tema. As metodologias decoloniais são pluralistas e se posicionam como uma ruptura desse tipo de pesquisa colonizadora que tem sido central para perpetuar a colonialidade em todos os seus aspectos.

Entretanto, pretende-se pensar o constitucionalismo de uma forma diferente. Com o objetivo de ir além dessa perspectiva "deslocalizada" do conhecimento, refletir-se-á sobre o discurso constitucional não como um saber oriundo de sujeitos universais que produziriam verdades universais, mas como um discurso que se fortalece a partir de um determinado tempo e lugar.

Optou-se por trabalhar a partir da analítica da modernidade/ colonialidade, a qual nos permite verificar como a ideia de constitucionalismo se constrói por meio de uma lógica colonialista, exploradora e genocida que, no entanto, justifica-se pelos projetos da modernidade construídos a partir de categorias "universais" como Constituição e Estado. Trata-se de ideias localizadas, que são impostas como sendo o melhor para todos e segundo as quais qualquer tipo de exploração e invasão é explicado como um caminho necessário para a realização plena da humanidade. O constitucionalismo, nesse contexto, 
assume historicamente um caráter moderno/colonial, que resulta na subalternização de todo e qualquer saber não enquadrado no modelo pretensamente universal de Constituição.

Uma possível ruptura com essa perspectiva moderno/colonial e subalternizadora do constitucionalismo pode ser observada com o chamado "novo constitucionalismo latino-americano". Ele surge a partir de sujeitos e saberes tradicionalmente subalternizados pela universalidade epistêmica, e apresenta diferentes elementos epistemológicos, políticos e jurídicos que o situam em um patamar diferenciado do constitucionalismo tradicional. Buscar-se-á, portanto, refletir sobre tais elementos, analisando como eles podem contribuir para uma descolonialidade do constitucionalismo, procurando enfatizar algumas práticas locais de solução de problemas pelo viés comunitário/ local.

\section{A analítica da modernidade/colonialidade e a universalidade epistêmica}

Muitos pensadores provenientes de diversas áreas refletem sobre a colonização como um grande evento prolongado e de muitas rupturas e não como uma etapa histórica já superada. ${ }^{1}$ A colonização não diz respeito apenas à administração colonial direta sobre determinadas áreas do mundo, mas refere-se a uma lógica de dominação, exploração e controle que inclui a dimensão do conhecimento. Nesse sentido, falase em colonialidade, e não apenas de colonialismo.

\footnotetext{
Tais teorizações são conhecidas como estudos pós-coloniais e descoloniais, estes últimos no âmbito da América Latina. Muitos dos estudos sobre a descolonialidade se deram no interior do grupo de investigação latino-americano "modernidade/colonialidade/descolonialidade". Este grupo começou a se estabelecer nos anos 1990, entretanto, seu amadurecimento se deu a partir de vários encontros a partir do ano 2000. Em Mundos y conocimientos de otro modo, Escobar (2003) faz uma apresentação geral do grupo, que no momento era chamado de "modernidade/ colonialidade" sem a categoria descolonialidade, inserido apenas a partir de maio de 2003. A história do surgimento e desenvolvimento desse grupo podemos também encontrar em: CASTRO-GÓMEZ; GROSFOGUEL, 2007.
} 
A palavra "colonialidade" é empregada para chamar atenção sobre o lado obscuro da modernidade, por isso, fala-se em modernidade/ colonialidade. A retórica da modernidade e suas ideias pretensamente universais (cristianismo, modernidade, Estado, democracia, mercado etc.) permitiram a perpetuação da lógica da colonialidade (dominação, controle, exploração, dispensabilidade de vidas humanas, subalternização do saberes dos povos colonizados etc.) (MIGNOLO, 2008, p. 293).

A colonialidade se sustentou e continua a se sustentar, portanto, a partir da construção do imaginário epistêmico da universalidade. Em nome de uma pretensa racionalidade universal, foram necessários o tráfico de escravos, a exploração dos indígenas e a expropriação de suas terras. Ou seja, a retórica positiva da modernidade justifica a lógica destrutiva da colonialidade.

Modernidade passou a ser - em relação com o mundo não europeu - sinônimo de salvação e novidade. Do Renascimento até o lluminismo, a modernidade teve como ponta de lança a teologia cristã, assim como o humanismo secular renascentista (ainda vinculado com a teologia). A retórica de salvação por meio da conversão ao cristianismo se traduziu em uma retórica de salvação por meio da missão civilizadora a partir do século XVII quando a Inglaterra e França substituíram a Espanha na liderança da expansão imperial/colonial ocidental. A retórica da novidade se complementou com a ideia de progresso. Salvação, novidade e progresso tomaram um novo rumo - e adotaram um novo vocabulário - depois da Segunda Guerra Mundial, quando os Estados Unidos substituíram a liderança da Inglaterra e França, deram apoio à luta pela descolonização na África e Ásia e iniciaram um projeto econômico global sob o nome de 'desenvolvimento e modernização'. Hoje conhecemos bem quais são as consequências da salvação por meio do desenvolvimento. A nova versão desta retórica, 'globalização e livre comércio', é a que se está em voga atualmente. (MIGNOLO, 2009, p. 43). 
Só aparece a modernidade e, nas sombras, são ocultadas as "coisas más", as quais se supõem que serão corrigidas com o "avanço da modernidade" e da democracia (exemplo, a política dos Estados Unidos no Iraque), quando se alcançar o estágio no qual a justiça e a igualdade se apliquem a todos. Escravidão, exploração e apropriação da terra são tratados como exceções e enganos, e não como a lógica consistente da colonialidade e sua inevitabilidade para o avanço da modernidade.

Se, por um lado, a colonialidade é a cara invisível de modernidade, é também, por outro lado, a energia que gera a descolonialidade.

A descolonialidade, entretanto, é um processo epistemológico que consiste principalmente em expor a lógica da colonialidade, a qual se estabelece epistemicamente a partir da universalidade epistêmica. Ou seja, se não modificarmos as formas de pensar e fazer, não mudaremos a lógica colonial que permeia a economia, a política ou o Direito.

A epistemologia ocidental que permitiu o desenvolvimento da modernidade/colonialidade se sustentou a partir do imaginário da existência de verdades universais, e fez isso principalmente ao anular a relação do sujeito com o processo de conhecimento. Castro-Gómez (2005, p. 18) fala no imaginário "ponto zero do conhecimento".

O ponto zero é o imaginário segundo o qual um observador do mundo social pode-se colocar em uma plataforma neutra de observação e, a partir dela, pode observar tudo e, ao mesmo tempo, não pode ser observado de nenhum ponto. Os habitantes do ponto zero, sejam cientistas ou filósofos, estão convencidos de que podem adquirir um ponto de vista sobre o qual não é possível adotar nenhum ponto de vista.

O "ponto zero" é um ponto de vista que se esconde e se oculta, e, ao fazer isso, coloca-se como diferente de qualquer outro. Como Deus, o observador observa o mundo de una plataforma inobservada. Essa visão através do "olhar de Deus" esconde sempre a sua perspectiva local e concreta sob um universalismo abstrato. 
É uma perspectiva de conhecimento na qual o sujeito epistêmico não tem sexualidade, gênero, etnicidade, raça, classe, espiritualidade, língua, localização epistêmica, tampouco está envolto em relações de poder. Ele produz a verdade a partir de um monólogo interior consigo mesmo, sem relação com o que está fora de si. Quer dizer, é uma perspectiva de conhecimento surda, sem rosto. O sujeito sem rosto flutua pelos céus sem ser determinado por nada nem por ninguém. (GROSFOGUEL, 2007, p. 64).

Os discursos construídos a partir desse imaginário ponto zero do conhecimento mascaram tanto a quem fala como o lugar de onde fala $e$ a época (tempo) em que é falado; além disso, ocultam todas as relações de poder que perpassam a construção discursiva. Desse modo, as verdades que se estabelecem como universais ocultam o fato de serem válidos a partir de uma "perspectiva dada" ou um "lócus de enunciação", da experiência geohistórica e biográfica do sujeito do conhecimento (MIGNOLO, 2007, p. 41).

Muitos discursos ocidentais (científicos, jurídicos, políticos) são considerados como "universais" e, assim, são impostos para todo planeta, diferentes dos saberes "outros" (indígenas, orientais e africanos), que são tratados como saberes menores, locais, incompletos, míticos, ou seja, inferiores.

As outras formas de ser, de organização da sociedade e de conhecimento são transformadas "não só em diferentes, mas em carentes, arcaicas, primitivas, tradicionais, pré-modernas. São colocadas num momento anterior do desenvolvimento histórico da humanidade." Ou seja, "aniquilação ou civilização imposta definem, destarte, os únicos destinos possíveis para os outros" (LANDER, 2005, p. 34).

No processo de desenvolvimento da "consciência moderna de tempo", as sociedades "atrasadas" são aquelas que não correspondem as práticas de vida europeias e ocidentais. Assim, as invenções do "bárbaro" e, depois, do "primitivo" foram os primeiros passos para sua tradução contemporânea como "subdesenvolvidos" e "emergentes". São situados no "antes", embora coexistam no "agora". Desse modo, o 
"outro" aparece como "objeto" fora do Ocidente e da Europa e, assim, fora da modernidade (MIGNOLO, 2010, p.63-64).

Quijano (2005, p. 254) assinala que com as ideias mitificadas de progresso e de um estado de natureza na trajetória humana todos os nãoeuropeus puderam ser considerados, de um lado, como pró-europeus e ao mesmo tempo dispostos, em certa sequência histórica e contínua, do primitivo ao civilizado, do irracional ao racional, do tradicional ao moderno, do mágico-mítico ao científico. Em outras palavras, do nãoeuropeu/pré-europeu a algo que com o tempo se europeizará ou modernizará.

Ou seja, o tempo é concebido como uma linha, e essa concepção é um elemento fundamental de um projeto civilizatório que sempre avança. Entretanto, esse tempo único é controlado pelo Ocidente. Ele é o presente a partir do qual se analisa todas as outras culturas do mundo.

O mito eurocêntrico da modernidade encontra sustentação em um sujeito que é capaz de chegar a uma verdade universal. Isso só é possível porque esse ego cogito cartesiano ${ }^{2}$ se constitui justamente ao encobrir-se enquanto sujeito concreto, mascarando sua localização nas relações de poder mundial. (GROSFOGUEL, 2007, p. 63).

Tal arrogância está na base dos projetos de muitos discursos, inclusive os jurídicos, pois a tradição do pensamento jurídico moderno/ colonial é representada como superior (paira acima) e é avançada temporalmente em relação a qualquer outra.

No âmbito do Direito, essa lógica, para Rubio (2010, p. 25), reduz, separa e abstrai o mundo jurídico em distintos planos.

2 O ego cogito (eu penso) cartesiano tornou-se o fundamento das ciências modernas ocidentais. "Mas, logo em seguida, adverti que, enquanto eu queria assim pensar que tudo era falso, cumpria necessariamente que eu, que pensava, fosse alguma coisa. $E$, notando que esta verdade: eu penso, logo existo, era tão firme e tão certa que todas as mais extravagantes suposições dos céticos não seriam capazes de abalar, julguei que podia aceitá-la, sem escrúpulo, como o primeiro princípio da Filosofia que procurava." (DESCARTES, 1973, p. 54, grifo nosso). 
Primeiro, reduz o Direito ao direito estatal, dessa maneira, ignora outras expressões jurídicas não estatais, isto é, oculta o pluralismo jurídico. Acredita, portanto, que o Direito só é norma ou instituição e, como consequência, absolutiza-se a lei do Estado e se burocratiza sua estrutura. Além disso, o saber jurídico fica reduzido à pura lógica analítica e normativa, de maneira que são ignoradas as suas conexões políticas e éticas.

Segundo, separa o âmbito do público e do privado, com as consequências negativas que, no âmbito das garantias, possuem os direitos humanos sob o predomínio da combinação entre as racionalidades instrumental e mercantil, por um lado, e a patriarcal ou machista, por outro. Separa também o jurídico do político, isto é, separa o direito das relações de poder.

Terceiro, abstrai o mundo jurídico do contexto sociocultural no qual se encontra e que o condiciona. Substitui-se o humano corporal, com necessidades e produtores de realidades, por seres sem atributos, fora da contingência e subordinados a suas próprias produções sóciohistóricas, como são o mercado, o Estado, o capital e o próprio Direito. Abstrai a tais níveis que os juristas acreditam que nossas ideias, categorias, conceitos e teorias são o que geram os fatos. Isto é, pairam acima da realidade, como se estivessem no imaginário ponto zero do conhecimento.

Como uma espécie de "endeusamento platônico", as ideias são confundidas com a realidade. Acredita-se que elas surgem a partir de um sujeito não situado, portanto, são universais, ou seja, válidas em qualquer lugar do planeta.

Pensar descolonialmente significa problematizar como essas ideias pretensamente universais e deslocalizadas são produzidas a partir de sujeitos localizados e demonstrar como as relações de poder que condicionam suas construções discursivas. Trata-se de proporcionar uma reflexão sobre o controle epistêmico, que possibilitou e continua possibilitando a existência de um sistema de conhecimento que atua 
reforçando a superioridade de determinados povos e conhecimentos em detrimento de outros.

No âmbito do Direito e do constitucionalismo, como se observa a seguir, significa ir além da ideia de que existiria uma única, verdadeira e universal forma de Estado e de constituição, que necessariamente deve ser herdeira do modelo liberal burguês.

\title{
3 O Iluminismo e suas verdades político-jurídicas universais
}

\begin{abstract}
A burguesia ${ }^{3}$, no final do século XVIII, era a classe responsável pelo desenvolvimento do comércio interno e externo, porém via-se refreada pelo poder absoluto do rei e da organização social em modelo estamental no seu desejo de ampliar suas relações comerciais. Sendo impedida de participar efetivamente da vida política, a burguesia passou a reivindicar uma sociedade fundamentalmente livre. Dessa maneira, passou a de defender as ideias que colocavam a lei, a figura do povo e a liberdade acima dos interesses dos reis, da nobreza e da Igreja (ALMEIDA, 2006, p. 49).
\end{abstract}

3 Segundo Trindade (2002, p. 24-25): “'Burgueses', inicialmente, era a denominação genérica dos habitantes dos 'burgos', pequenas cidades que surgiam nos cruzamentos de rotas comerciais, ou ao longo dessas rotas, às vezes fortificadas para proteger as caravanas contra os inúmeros bandos de salteadores que proliferavam nas estradas naquele tempo. De modo esperável, à medida em que iam crescendo passaram a aglomerar toda sorte de pessoas 'livres' [...] Com o tempo, aos poucos, uma parte desses citadinos conseguiu acumular algum capital nas práticas do comércio, da usura (apesar da condenação da Igreja aos empréstimos com juros) e da exploração de força de trabalho alheia (ainda em pequena escala), empreitando a produção de artefatos de uso corrente, artigos de luxo para consumo da nobreza ou equipamentos para as guerras intermitentes, vindo a constituir uma pequena elite economicamente independente que, por não se ocupar de trabalhos braçais e ostentar um padrão de vida superior, discernia-se da massa dos habitantes dos burgos e das cidades maiores. Nos séculos XV e XVI, esta classe burguesa stricto sensu já era muito ativa e influente na maioria das cidades da Europa ocidental. Emprestava dinheiro a reis, a mercadores, a senhores feudais em dificuldades, fornecia assessores competentes para a administração do Estado monárquico, e estava envolvida em todos os negócios florescentes da época, como bancos, construção naval, abertura de manufaturas e exploração dos "novos mundos" incorporados pelas grandes descobertas marítimas. Nos séculos XVII a XVIII, a burguesia já estava bastante diversificada em vários extratos, desde os mestres artesãos que expandiram suas oficinas contratando muitos empregados e montando manufaturas, até grandes (para a época) industriais e banqueiros, e constituía o que podia ser chamado de uma 'classe média' - no sentido de setores intermediários entre a aristocracia e a grande massa do povo." 
A ideia da primazia das leis - defendida por Montesquieu -em substituição ao direito absoluto e divino do rei e a ideia da liberdade para investir e produzir, visando o enriquecimento não apenas individual, mas da nação defendida no final do século XVIII por Adam Smith - em detrimento do ideal do mercantilismo monopolista, além da defesa da liberdade de credo, do afastamento da Igreja em relação ao Estado - como colocavam os anti-clericalistas do lluminismo francês - e da liberdade dos homens e autodeterminação dos povos, seriam os fundamentos do ideário liberal que levaria a burguesia europeia a contestar e a derrubar o Ancien Régime que, até então, a impedia de ampliar as possibilidades políticas e econômicas oferecidas pela ordem capitalista. (ALMEIDA, 2006, p. 49).

O empenho em estender os seus domínios para todo o globo, além do caráter comercial, revestiu-se da ideologia iluminista, que foi útil aos propósitos coloniais da burguesia em ascensão.

O lluminismo surgiu no século XVIII, fundamentado no ideal das "luzes", caracterizava-se principalmente pela crença na racionalidade humana e esta era considerada como universal. Como o homem (branco, europeu, ocidental) teria a faculdade da racionalidade, ele poderia conceber racionalmente verdades universais. Exaltava-se o papel da ciência, entendida enquanto metalinguagem universal, capaz de expressar rigor e objetividade.

O século XVIII, o século das "luzes", estava profundamente imbuído na "convicção no progresso do conhecimento humano, na racionalidade, na riqueza e no controle sobre a natureza". O lluminismo derivou sua força primordialmente do evidente progresso da produção, do comércio e da racionalidade econômica e científica (HOBSBAWM, 1996, p. 28).

O pensador iluminista acreditava na evolução e no progresso. No discurso sobre a história da humanidade, os povos colonizados pela Europa apareceram no nível mais baixo da escala de desenvolvimento, enquanto a economia de mercado, a nova ciência e as instituições 
político-jurídicas modernas são apresentadas como último estágio da evolução social, cognitiva e moral da humanidade (CASTRO-GÓMES, 2005, p. 42).

Conforme Hobsbawm (1996, p. 41), o pensamento "esclarecido" era dominado por um individualismo secular, racionalista e progressista. Tratava-se de libertar o indivíduo das algemas que o agrilhoavam, isto é, do tradicionalismo ignorante da Idade Média, da superstição das igrejas (distintas da religião "racional" ou "natural") e também da irracionalidade que dividia os homens em uma hierarquia de patentes mais baixas e mais altas de acordo com o nascimento ou algum outro critério irrelevante.

A liberdade, a igualdade e, em seguida, a fraternidade de todos os homens eram seus slogans. No devido tempo se tornaram os slogans da Revolução Francesa. O reinado da liberdade individual não poderia deixar de ter as consequências mais benéficas. Os mais extraordinários resultados podiam ser esperados - podiam de fato já ser observados como provenientes - de um exercício irrestrito do talento individual num mundo de razão. (HOBSBAWM, 1996, p. 41).

Com o lluminismo, segundo Toulmini (1990, p. 67), aparece, a partir de um ponto de vista científico, a pretensão de elaborar um tipo de conhecimento que tenha o homem e a sociedade como objetos de estudo submetidos à exatidão das leis físicas. Já de um ponto de vista político, a pretensão é criar uma sociedade ordenada a partir do Estado.

O Estado aparece, então, como uma criação racional do homem e entregue ao soberano mediante um contrato. A sociedade era formada, desse modo, pela união de homens livres, unidos em função de uma livre escolha.

Antes de se dar esse pacto, os pensadores iluministas explicavam que os homens viviam em um estado de natureza. Compartilhava-se a ideia de que, em um passado mais ou menos remoto, todos os povos do mundo tinham conhecido uma vida social que, por sua geral simplicidade e pela ausência de certas instituições específicas (tais como a propriedade 
privada da terra, o governo centralizado, as diferenças de classes e as religiões governadas por sacerdotes), contrastava sensivelmente com a ordem social da moderna Europa. Essa primeira fase da evolução era chamada de "estado de natureza". (HARRIS, 1979, p. 33).

mbora as caracterizações concretas do "estado de natureza" (Hobbes, Locke e Rousseau) divergissem consideravelmente, a explicação sobre o modo como os homens saíram do estado de natureza e chegaram às instituições e aos costumes que existiam na Europa era semelhante. Em geral, aceitava-se que o grande motor da história e a primeira causa das diferenças de usos e costumes eram as variações na efetividade do raciocínio. Acreditava-se que o homem civilizado tinha saído do estado de natureza literalmente pelo poder de seu pensamento, inventando constantemente instituições, costumes e técnicas de subsistência cada vez mais inteligentes, mais racionais (HARRIS, 1979, p. 33).

O alicerce a partir do qual se constrói o Estado moderno burguês e iluminista é a ideia de nação. Conforme Magalhães (2008, p. 47), a tarefa de construção do Estado moderno dependia da construção de uma identidade nacional. Tratava-se da "imposição de valores comuns que deveriam ser compartilhados pelos diversos grupos étnicos, pelos diversos grupos sociais para que assim todos reconhecessem o poder do estado". ${ }^{4}$

Segundo Santos (2007, p. 31), o conceito liberal de nação faz referência à coincidência entre nação e Estado. A nação seria o conjunto de indivíduos que pertencem ao mesmo espaço geopolítico do Estado. Desse modo, os Estados modernos chamam-se Estado-nação, uma nação correspondendo a um Estado.

Nesse cenário, o constitucionalismo moderno representaria um ato livre dos povos, aos quais se impõe uma regra a partir de um contrato

A construção do Estado-nação, algo abstrato, consolidou-se primeiro na Europa, com Portugal, Espanha, França e Inglaterra, a partir do momento em que aumenta o poder do Rei em relação aos senhores feudais e Igreja. 
social para viver em paz no interior de um Estado-nação (SANTOS, 2007, p. 33).

Trata-se, porém de uma simplificação brutal da vida, pois as pessoas têm família, cultura, falam determinada língua, possuem identidades, vivem em aldeias ou na cidade e repentinamente convertem-se em indivíduos que formam uma nação. Em meio a diversas culturas, uma se impõe como hegemônica, como a mais avançada, que é a cultura representada pelo Estado-nação (SANTOS, 2007, p. 34).

Segundo Santos (2007, p.33), essa simplificação, realizada a partir do Estado-nação e do constitucionalismo moderno, é uma forma de luta da burguesia contra os usos e costumes do Sacro Império Romano contra as identidades feudais, pois essa ideia de usos e costumes impedia o desenvolvimento da burguesia ascendente, que está por trás do constitucionalismo moderno.

Precisa-se criar uma regularidade institucional, que passa pelo governo representativo, pelo primado do Direito, da separação de Poderes e da liberdade individual (SANTOS, 2007, p. 34).

A formação do Estado moderno e do constitucionalismo que com ele nasce está relacionada, portanto, com a uniformização dos modos de vida, com a intolerância religiosa, cultural e também com a negação da diversidade fora de determinados padrões e limites (MAGALHÃES, 2008, p. 47).

O Estado-nação surge como um fenômeno artificial imposto pela violência e baseado na repressão das tradições locais prévias. A identidade é concebida não como a resolução das diferenças sociais e históricas, mas como um produto de uma unidade primordial (RESTREPO, 2009, p. 310).

Conforme Restrepo (2009, p. 310), o Estado-nação consolida a imagem particular e hegemônica da sociedade moderna, a imagem da vitória da burguesia, que adquire, assim, um caráter universal.

O Estado-nação é construído como uma verdade político-jurídica universal. Um modelo universal de cultura que é ocidental e estabelece 
um exterior e interior da verdade política e jurídica. Obriga a ocultação da diferença e a submissão da humanidade aos significados e conceitos rígidos, impostos a partir de um lócus de enunciação local que se pretende universal.

Por meio da redução da multiplicidade à força do "um", a nação converte-se em veículo colonial. A soberania nacional permite reduzir as diferenças de um mundo múltiplo. Isso implica que o mesmo modelo de humanidade está estabelecido no interior das dimensões do Estadonação. É um modelo para o mundo colonizado, pois nele deve residir o verdadeiro valor da humanidade cultural, social, econômica e política.

\section{O constitucionalismo moderno/colonial}

O ideário constitucionalista liberal burguês surge a partir do momento em que se consolida o Estado-nação. Esse ideário é pautado na ideologia iluminista e na invenção de verdades político-jurídicas pretensamente universais, resultado da crença de que a racionalidade do homem (homem, nesse sentido, é branco e ocidental) é capaz de chegar à verdade não só em relação natureza, mas também em relação à sociedade.

Conforme Bonavides (2004, p. 37), o termo “constituição" ingressou na linguagem jurídica para exprimir uma técnica de organização do poder aparentemente neutra. No entanto, encobria, em profundidades invisíveis, desde o início, a ideia de sua legitimidade, que eram os valores do pensamento liberal iluminista.

Para o pensamento iluminista, liberal e burguês, a legítima constituição era a jurídica; as demais formas deveriam ser combatidas. A verdadeira constituição deveria observar a liberdade individual e o estabelecimento de limites para os Poderes do Estado. Se não tivesse essas características liberais, não se poderia falar em constituição. 0 artigo 16 da Declaração dos Direitos do Homem e do Cidadão dizia: "Toda sociedade na qual não esteja assegurada a garantia dos direitos nem determinada a separação dos poderes, não tem constituição." (BONAVIDES, 2004, p. 38-39). 
Evidentemente, a burguesia não prolatou tais valores como seus. Ao contrário, conferiu-Ihes um caráter universal. Apresentou a separação de Poderes e os direitos individuais como imposições oriundas da própria razão humana e, por conseguinte, pertinentes ao gênero humano como um todo. Desse modo, os pensadores liberais lograram êxito em conferir um caráter abstrato e genérico aos princípios e direitos que constituíam precipuamente o interesse da classe que representavam (BONAVIDES, 2004, p. 37).

Segundo Médici (2010, p. 100), a ideia de constituição no constitucionalismo liberal baseava-se na crença da possibilidade de uma racionalidade normativa das instituições. $O$ individualismo supõe os direitos inerentes aos seres humanos e, ao mesmo tempo, propõe que estes são os átomos que movem a física social e que, ao perseguir seus interesses, geram ordem e bens públicos. A arquitetura institucional da divisão dos Poderes do "sistema de freios e contrapesos" expressa a crença racionalista na analogia entre a física e a mecânica da época, e a estruturação da ordem e do sistema social possível e desejável.

O estudo da constituição era entendido, portanto, como algo neutro, apolítico, a-histórico. Tratava-se de um Direito constitucional que aspirava dar ao Estado-nação as bases permanentes de sua organização segundo as correntes do pensamento jurídico iluminista, tomado então como definitivo, absoluto, eterno, imutável.

O constitucionalismo foi utilizado pelos liberais burgueses para a formalização de seus valores ideológicos, políticos, doutrinários e filosóficos, ou seja, para a defesa dos seus interesses concretos. Entretanto, vestiu-se de uma aura de universalidade, como todo conhecimento europeu pretensamente se autodesignava.

Sem dúvida, abaixo da filosofia do século XVIII, o interesse da burguesia revela-se facilmente, pois ela deveria tirar as maiores vantagens do novo regime. Mas ela acreditava sinceramente trabalhar pelo bem da humanidade. E mais: estava persuadida de preparar a chegada de uma nova era da justiça e do direito. (LEFEBVRE, 1989, p. 71). 
Por conseguinte, universalizaram-se os valores da burguesia reinante com a cristalização da exigência de que as constituições contemplassem o princípio da separação dos Poderes e estabelecessem os direitos individuais.

O discurso constitucional liberal burguês foi importado para a América Latina, que apenas seguiu os mesmos parâmetros de divisão das funções do Estado. Esse modelo de constituição significou, no melhor dos casos, igualdade jurídica formal e, com isso, invisibilizou as desigualdades fáticas de classe, etnia, gênero e culturas. O monismo jurídico e cultural das constituições liberais ignorou a pluralidade e as diferenças (MÉDICI, 2010, p. 101).

A influência do discurso da civilização (tomando como base a sociedade europeia) contra a barbárie, processo que levaria ao progresso social, implicou narrativas que se encontram no constitucionalismo liberal do século XIX (MÉDICI, 2010, p. 101).

Ou seja, por trás dos discursos dos benefícios da civilização - e, neste caso, do constitucionalismo -, ocultou-se o genocídio das comunidades originárias e, no melhor dos casos, sua subordinação aos modelos e instituições universalistas europeias, justificadas como necessárias para o que se chamou de progresso e desenvolvimento da humanidade.

Observa-se, assim, o caráter moderno/colonial do constitucionalismo: ele se constrói a partir de uma retórica moderna de civilização e progresso, porém encobre a lógica colonial de sujeição e exploração.

Mesmo diante das mudanças do constitucionalismo surgidas a partir do século $\mathrm{XX},{ }^{5}$ em geral foram deixadas de lado as críticas relativas às relações coloniais e à universalidade epistêmica. Nesse cenário, não

5 O constitucionalismo do Estado de Direito e da sociedade liberal passou, a partir do século $\mathrm{XX}$, a abrir espaço para o constitucionalismo político e social. Mantém-se o núcleo liberal de direitos individuais e ampliam-se os direitos sociais relativos ao trabalho, à saúde, à educação, à previdência, e os direitos econômicos. Marcos dessa modificação foram a Constituição do México, de 1917, e da Alemanha, de 1919. 
se questionou o monismo, o Estado-nação e o sujeito de conhecimento do constitucionalismo; tampouco foi debatida sua fundamentação contratualista baseada na racionalidade dos seres humanos, a partir do modelo racional ocidental.

A imagem simbólica que o Direito e o constitucionalismo contemporâneo continuam a propor é a de uma pirâmide jurídica. No topo, de forma hierárquica, localiza-se a constituição. Esse simbolismo é amplamente difundido e utilizado como recurso pedagógico no ensino do Direito para explicar as características do sistema jurídico, entendido como um sistema hierárquico, logicamente coerente e fechado, e a função da constituição como fundamento de validade das normas inferiores (MÉDICI, 2010, p. 96).

A constituição estabeleceria, desse modo, a si mesma, e seria válida conforme sua própria sistematicidade, fora da realidade. A validade da normatividade jurídica não estaria assentada na legitimidade das pessoas, do povo, mas em sua particularidade autônoma e apolítica (RESTREPO, 2009, p. 109).

Da mesma forma que o sujeito do conhecimento estaria separado da realidade histórica e política, suas ideias e instituições, também. Esse modelo (a constituição como algo que paira acima da realidade) reflete os ideários racionalistas e a universalidade epistêmica, porém, não é mais que uma abstração fictícia que oculta a modernidade/colonialidade. O "universal" é definido pelo homem branco e ocidental em um processo colonial de inferiorização dos demais povos e saberes.

\section{O novo constitucionalismo latino-americano e a descolonialidade/decolonialidade}

A descolonialidade no âmbito do constitucionalismo implica problematizar a construção epistemológica que permitiu que a constituição nos moldes liberais burgueses se estabelecesse como válida universalmente, subalternizando qualquer outra forma de 
organização social. Trata-se, sobretudo, de uma busca por ressignificar a ideia de constituição, mesmo sendo consciente de que esta foi, em suas raízes liberais burguesas, uma retórica moderna para encobrir a lógica colonial.

De acordo com a analítica da modernidade/colonialidade, a constituição, como um universal, não é nada mais que um discurso particular, localizado, que se impõe a partir de um imaginário ponto zero do conhecimento, o qual tem como função primordial subalternizar a diferença. A constituição não seria a origem do poder ou a base que estabelece o Direito, e sim o resultado de um momento histórico e de determinadas relações de poder.

Nesse cenário problematizador da lógica colonial, podemos destacar alguns elementos do "novo constitucionalismo latinoamericano" que visivelmente abrem as portas para uma descolonialidade constitucional.

Destacam-se principalmente os processos constituintes na Bolívia (2006-2009) e no Equador (2007-2008), que surgem a partir dos processos de mobilização social e da instalação de novos governos apoiados nas maiorias populares, com grande participação das comunidades originárias e campesinas. Busca-se principalmente adequar a constituição jurídica formal às complexidade dessas culturas e sociedades (MÉDICI, 2010, p. 98).

De acordo com Rubio (2010b, p. 24), esse novo constitucionalismo incorpora em suas cartas magnas os direitos de caráter coletivo relacionados com os povos indígenas e/ou grupos afrodescendentes, como o direito à terra, à autodeterminação e à autonomia, direitos culturais, educação, idioma, usos e costumes. Tratam-se de direitos sistematicamente negados ao longo de uma trágica história de resistência, exploração, genocídio e barbárie. Além disso, são incorporados os direitos ambientais, que protegem a biodiversidade e o meio ambiente, conforme estes são entendidos pelas culturas milenárias. Nesse sentido, a Constituição equatoriana considera a natureza como sujeito de direitos, e, como tal, deve ser tratada e cuidada. 
A constituição, da mesma forma que a ideia de Estado, não é considerada uma verdade universal que paira acima das relações humanas - ela provém do povo (povo não como algo fixo e inerte). Portanto, o estudo do Direito constitucional não é fechado e limitado, mas algo complexo.

Segundo Médici (2010, p. 121), mais que estar no topo de uma pirâmide, a constituição é horizontal e constitui o centro de sentidos no qual se sobrepõem os saberes e práticas de uma pluralidade de culturas. As soluções que propõe para reconhecer e coordenar tais direitos plurais impregnam cada uma das práticas constitucionais.

Esse constitucionalismo latino-americano se distingue do constitucionalismo moderno/colonial por vários elementos potencialmente descoloniais. Destacam-se aqui cinco deles.

Primeiro, surge a partir de lugares tradicionalmente subalternizados, ou seja, considerados inferiores sob a lógica colonial do conhecimento. Lugares de não pensamento (lugares de mitos, de religiões não ocidentais, de folclore, sem educação formal, de subdesenvolvimento), que hoje estão despertando do processo de colonialidade e demonstrando a existência de diferentes formas de compreender o mundo. Ou seja, essas novas constituições não visam apenas favorecer e incluir as diferentes culturas, mas surgem a partir dessas próprias culturas historicamente consideradas incapazes de produzir conhecimento.

Segundo, o discurso constitucional não é considerado privilégio dos constitucionalistas formados em universidades, mas das pessoas, dos povos, da mobilização indígena, por exemplo. Fratura-se, desse modo, com o discurso constitucional que historicamente disfarça sua lógica colonial através do discurso moderno da neutralidade, objetividade e cientificidade. Questiona-se, portanto, a exigência colonial epistêmica de que os saberes, para se constituírem como verdadeiros e válidos, devem partir de um imaginário ponto zero do conhecimento, seja este o Estado, a academia ou outros. 
Terceiro, o novo constitucionalismo latino-americano não pretende ser algo construído separado do tempo e do espaço, das relações políticas e históricas. Pelo contrário, reflete principalmente as diversas culturas andinas e não aspira ser um modelo único para todos os povos do planeta. Os objetivos modernos de encontrar fórmulas para definir e "salvar" a humanidade como um todo é substituído pela pluriversalidade epistêmica, diferentes sujeitos de conhecimento, diferentes locais de enunciações, diferentes propostas que surgem muitas vezes a partir da ressignificação de uso contra-hegemônico de conceitos universalistas moderno/coloniais, como Estado, democracia, direitos humanos, entre outros.

Quarto, diferentemente do constitucionalismo tradicional, que tem como núcleos o Estado-nação e a uniformidade de todas as culturas a partir de uma cultura pretensamente mais avançada, o novo constitucionalismo latino-americano pretende refundar o Estado por meio da construção de Estados plurinacionais. O Estado plurinacional, segundo Garcés (2009, p. 176), é um "estado de consorciação onde as coletividades políticas opinam, expressam seu acordo e tomam decisões sobre as questões centrais do estado." A ideia de que o Estado tem soberania única e absoluta sobre seu território é desfeita e, desse modo, possibilita-se o exercício do autogoverno (para dentro) e do cogoverno (em relação ao Estado central e com as outras entidades territoriais). (GARCÉS, 2009, p. 176).

Quinto, o novo constitucionalismo latino-americano incorpora diversas epistemologias tradicionalmente silenciadas e marginalizadas pela modernidade/colonialidade. Para essas outras formas de conhecer os projetos modernos de civilização, progresso e desenvolvimento não fazem muito sentido, pois se busca a vida em harmonia, o sumak kawsay (quechua) e o suma qamaña (aymara).

Sumak kawsay e suma qamaña são expressões que estão presentes tanto na Constituição do Equador como na Constituição da 
Bolívia. ${ }^{6}$ O princípio fundamental do sumak kawsay e suma qamaña, diferente da lógica capitalista (marcada pela ideologia da depredação, consumo e competição), resulta numa visão holista e de interação entre sociedade e natureza como marco necessário para a harmonia da pacha. $^{7}$

O suma qamaña, segundo explica o intelectual aymara, Simón Yampara (2010), é um modo de existência que está em harmonia e equilíbrio com todos outros elementos da pacha, uma vida em comunidade e harmonia com todos os outros seres. Procura-se o consenso entre as oposições complementares, um ponto de interrelação entre duas forças ou energias, no sentido de estabelecer o ponto de encontro ou centro (taypi) entre dois elementos, forças, poderes ou posições complementares.

O novo constitucionalismo latino-americano, dessa forma, representa uma perspectiva descolonial, que vai além do constitucionalismo tradicional, mostrando que é possível fraturar os modelos universalistas da modernidade/colonialidade. Surge a partir dos sujeitos tradicionalmente subalternizados, problematiza o imaginário do ponto zero do conhecimento e a universalidade epistêmica, pautase na ideia de Estado plurinacional e, assim, questiona o âmago da subalternização de culturas. Principalmente, abre espaço para diferentes epistemologias silenciadas, demonstrando a existência de distintas

6 A Constituição Equatoriana de 2008 diz que "se reconoce el derecho de la población a vivir en un ambiente sano y ecológicamente equilibrado, que garantice la sostenibilidad y el buen vivir, sumak kawsay". A Constituição Boliviana de 2009 recolhe uma pluralidade de termos linguísticos do país e diz que "el estado asume y promueve como principios ético-morales de la sociedad plural: ama qhilla, ama llulla, ama suwa (no seas flojo, no seas mentiroso ni seas ladrón), suma qamaña (vivir bien), ñandereko (vida armoniosa), teko kavi (vida buena), ivi maraei (tierra sin mal) y qhapaj ñan (camino o vida noble)".

7 Para Fernández-Osco (2009, p.13), em todos os âmbitos da vida andina, aymara e quechua, fala-se da pacha, que em termos muito simples trata-se do tempo e espaço no qual todos acham-se inseridos. Aymará é o nome do povo cuja língua também se chama aymará, sua maior concentração fica na Bolívia, no Peru, no norte do Chile e na Argentina. A denominação quechua refere-se aos povos que falam o quéchua, os quais vivem principalmente na região andina (Equador, Peru e Bolívia). O idioma é falado hoje por cerca de 10 milhões de pessoas, sendo o idioma "nativo" mais falado na América do Sul. 
formas de organização social, econômica, política e jurídica, baseadas em diferentes formas de se compreender o mundo.

Entretanto, tais elementos descoloniais presentes nesse novo constitucionalismo latino-americano não significam uma mudança imediata e total do imaginário moderno/colonial para um modelo de Estado e constituição descolonial. Evidenciam, sobretudo, rupturas cruciais que podem propiciar o inicio de um processo descolonizador, localizado e pluriversal que provavelmente se estenderá ao longo deste século para todos os âmbitos do pensamento político e jurídico.

\section{Conclusão}

Com este trabalho, busca-se, inicialmente, demonstrar como o atual constitucionalismo, de origem iluminista, liberal e burguesa, possui uma face moderna (com as promessas de progresso e civilização) que oculta um sistema de colonialidade (com opressão, exploração, genocídios).

A lógica colonial foi construída principalmente a partir de um aparato de conhecimento que permite o estabelecimento da ideia de universalidade epistêmica, ou seja, parte do pressuposto que existiriam sujeitos capazes de chegar a verdades universais, válidas para toda a humanidade. Tais sujeitos, historicamente, podem ser localizados como os que se autoproclamam "brancos" e "ocidentais". Eles possuíram uma capacidade racional avançada e superior em relação às demais culturas e essa relação de conhecimento imposta globalmente permitiu a construção da modernidade/colonialidade.

Nesse cenário, o constitucionalismo não buscou apenas inculcar a constituição nos moldes liberais, mas se incutir colonialmente todo um aparato epistêmico, localizado como se fosse universal e válido para todos os povos do planeta. Desse modo, pode-se falar em um constitucionalismo moderno/colonial. 
Portanto, para se realizar um processo de ruptura da lógica colonial, é imprescindível que se questione a universalidade epistêmica.

Para o pensamento descolonial, não há verdade absoluta, universal, uma "verdade sem parênteses", pois todas as verdades devem estar entre parênteses, ou seja, são válidas em determinado contexto, determinado mundo explanativo. Dessa maneira, abre-se a perspectiva de se construir mundos abertos e plurais, mais dialógicos e compreensivos, sem a pretensão de que exista alguém que habite o lugar supremo capaz de determinar o que é verdadeiro e universal. Isto é pluriversalidade, e não universalidade epistêmica.

No âmbito do constitucionalismo, é possível verificar elementos desse processo descolonial no chamado "novo constitucionalismo latinoamericano". Sobretudo, verifica-se um questionamento dos marcos teóricos e epistêmicos do constitucionalismo moderno/colonial e uma ressignificação deste a partir de sujeitos e saberes tradicionalmente subalternizados.

Trata-se de um processo descolonial do constitucionalismo que pode representar uma mudança de época, com diferentes forças atuantes, a partir de diferentes formas de pensamento, que não almejam se estabelecer como universais.

8 Utilizo aqui a pertinente distinção entre "verdade sem parênteses" e "verdade entre parênteses", de Humberto Maturana. Ele também desenvolve a ideia de "variadas objetividades" e de "multiverso", em vez de "universo" (isto é, a ideia hegemônica de universalidade passa a ser no pensamento de Maturana, um componente a mais de um mundo multiversal). Maturana fala ainda de objetividade entre parênteses e sem parênteses. O observador que habita a objetividadeentre-parênteses se dá conta de que habita um multiverso, isto é, habita variados e diferentes (igualmente legítimos) mundos explanativos. Cada desacordo explicativo é um convite para uma responsável reflexão de coexistência (conflitiva e dialógica), e não uma irresponsável negação da outra explicação. Já o observador que habita a objetividade-sem-parênteses acredita que todos aqueles que não estão de acordo com o que ele sente ou pensa não tem razão de ser ou está errado. Ou seja, coloca-se em uma posição de juiz supremo e acusa as opiniões diferentes (MATURANA, 1997). 


\section{Referências}

ALMEIDA, Ivete Batista da Silva. Liberalismo e neoliberalismo: fases da construção da sociedade e da economia capitalista atual no ocidente e no oriente. Olhares \& Trilhas, Uberlândia, ano VII, n. 7, p. 47-56, 2006.

\section{BARROSO, Luís Roberto. Curso de direito constitucional} contemporâneo: os conceitos fundamentais e a construção do novo modelo. São Paulo: Saraiva, 2009.

BONAVIDES, Paulo. Curso de direito constitucional. 15. ed. São Paulo: Malheiros, 2004.

CASTRO-GÓMEZ, Santiago. La hybris del punto cero: ciencia, raza e ilustración en la Nueva Granada (1750-1816). Bogotá: Pontificia Universidad Javeriana, 2005.

; GROSFOGUEL, Ramón. Prólogo: giro decolonial, teoría crítica y pensamiento heterárquico. In: CASTRO-GÓMEZ, Santiago; GROSFOGUEL, Ramón. El giro decolonial. Reflexiones para una diversidad epistémica más allá del capitalismo global. Bogotá: Siglo del Hombre-lesco-Pensar, 2007. p. 9-23.

\section{FERNÁNDEZ-OSCO, Marcelo. El Ayllu y la reconstitución del} pensamiento aymara. 2009, $247 \mathrm{f}$. Tese (Doctor of Philosophy in the Department of Romance Studies) - Graduate School of Duke University, Durham, 2009.

GARCÉS, Fernando. Os esforços de construção descolonizada de um Estado plurinacional na Bolívia e os riscos de vestir o mesmo cavalheiro com um novo paletó. En: VERDUM, Ricardo (Org.). Povos indígenas: constituições e reformas políticas na América Latina. Brasília: Instituto de Estudos socioeconômicos, 2009. p. 167-192.

GROSFOGUEL, Ramón. Descolonizando los universalismos occidentales: el pluri-versalismo transmoderno decolonial desde Aimé Césaire hasta los zapatistas. En: CASTRO-GÓMEZ, Santiago; GROSFOGUEL, Ramón (Ed.). El giro decolonial: reflexiones para 
una diversidad epistémica más allá del capitalismo global. Bogotá: Siglo del Hombre-lesco-Pensar. 2007. p. 63-78.

HARRIS, Marvin. El desarrollo de la teoria antropologica. Madri: Siglo Veintiuno, 1979.

HOBSBAWM, Eric J. A era das revoluções: 1789/1848. 9. ed. São Paulo: Paz e Terra, 1996.

LANDER, Edgardo. Ciências sociais: saberes coloniais e eurocêntricos. In: . (Org.). A colonialidade do saber: eurocentrismo e ciências sociais. Perspectivas Latino-Americanas. Tradução de Júlio César Casarin Barroso Silva. Buenos Aires: CLACSO, 2005. p. 21-53.

LEFEBVRE, Georges. 1789: o surgimento da Revolução Francesa. São Paulo: Paz e Terra, 1989.

MAGALHÃES, José Luiz Quadros de. Identidades e identificações: da possibilidade de construção de uma ética universal. Veredas do Direito, Belo Horizonte, v. 5, n. 9/10, p. 45-61, jan./dez. 2008.

MATURANA, Humberto. La objetividad, un argumento para obligar. Santiago de Chile: Dolmen, 1997.

MÉDICI, Alejandro. Teoría constitucional y giro decolonial: narrativas y simbolismos de las constituciones Reflexiones a propósito de la experiencia de Bolivia y Ecuador. Otros Logos. Revista de estúdios críticos. CEAPEDI, Neuquén, ano 1, n. 1, p. 94-124, 2010.

MIGNOLO, Walter. Desobediência epistêmica: a opção descolonial e o significado de identidade em política. Cadernos de Letras da UFF, Dossiê: Literatura, língua e identidade, Niterói, n. 34, p. 287-324, 2008.

. Desobediencia epistémica: retórica de la modernidad, lógica de la colonialidad, y gramática de la descolonialidad. Buenos Aires: Ediciones del Signo, 2010.

. La colonialidad: la cara oculta de la modernidad. In: Museo de Arte Moderno de Barcelona: catalog of museum exhibit: Modernologies. 2009. 
Disponível em: <http://www.macba.es/PDFs/walter_mignolo_ modernologies_cas.pdf> Acesso em: 1 set. 2010.

. La idea de América Latina: la herida colonial y la opción descolonial. Barcelona: Gedisa, 2007.

QUIJANO, Aníbal. Colonialidade do poder, eurocentrismo e América Latina. In: LANDER, Edgardo (Org.). A colonialidade do saber: eurocentrismo e ciências sociais: perspectivas latino-americanas. Tradução de Júlio César Casarin Barroso Silva. Buenos Aires: CLACSO, 2005. p. 227-277.

RESTREPO, Ricardo Sanín. La democracia em tu cara. Revista Filosofia Unisinos, São Leopoldo, v. 10, n.1, p. 92-115, jan./abr. 2009.

RUBIO, David Sánchez. Confrontar la simplificación del mundo jurídico. Jornal Estado de Direito, Porto Alegre, ano 5, n. 28, p. 25, 2010.

. Desafíos contemporáneos del derecho: diversidad, complejidad y derechos humanos. Revista del Instituto de Investigaciones Jurídicas, San Luis Potosí, n. 1, p. 9-31, jul./dez. 2010b.

SANTOS, Boaventura de Sousa. La reinvención del Estado y el Estado plurinacional. Revista OSAL (CLACSO), Buenos Aires, ano VIII, n. 22, p. 25-46, 2007.

TRINDADE, José Damião de Lima. História social dos direitos humanos. São Paulo: Petrópolis, 2002.

TOULMIN, Stephen. Cosmopolis: the hidden agenda of modernity. Chicago: Chicago University Press, 1990.

YAMPARA, Simon. O bem-viver como perspectiva ecobiótica e cosmogônica. IHU on line: Revista do Instituto Humanitas Unisinos, São Leopoldo, ano 10, n. 340, p. 19-22, ago. 2010.

Recebido em: 01/04/2015

Aprovado em: 15/07/2015 